\title{
Effect of flow recirculation on pulp quality and energy efficiency in low consistency refining of mechanical pulp
}

\section{Christer Sandberg and Jan-Erik Berg}

KEYWORDS: Low consistency refining, Flow recirculation, Fibre properties, Energy efficiency, Mechanical pulping, TMP

SUMMARY: The effect of pulp flow recirculation on energy efficiency and pulp properties development in low consistency refining of TMP has been studied. Trials were made with TwinFlo 58 refiners in two mills in Sweden. The refiners were operated at constant specific refining energy but different flow conditions.

No effect of recirculation was seen on refining energy efficiency, pulp quality or fibre wall delamination /internal fibrillation. At high degree of recirculation though, a somewhat larger fibre length reduction was seen. This means that a large degree of recirculation can be used to attain a high specific energy in one stage low consistency refining, without significant negative effects on fibre properties. If a high specific energy input is desirable, it is more cost effective to install one large refiner with recirculation compared to several small without recirculation in series.

When recirculation was increased by means of increased flow through the refiner, the outlet pressure dropped. The lower pressure drop over the refiner probably decreased the internal recirculation between rotor and stator, which could explain the observation that there was little effect on fibre development by recirculation. This means that at certain conditions the distribution in fibre treatment might not increase so much when the outer recirculation is increased, since the internal recirculation might be reduced simultaneously.

\section{ADDRESSES OF THE AUTHORS: Christer Sandberg (christer.sandberg@holmenpaper.com) and Jan-Erik Berg (jan-erik.berg@miun.se) \\ FSCN, Department of Chemical Engineering, Mid Sweden University, SE-851 70 Sundsvall, Sweden. \\ Corresponding author: Christer Sandberg}

Low consistency (LC) refiners are designed for rather low specific energy input at high production compared to high consistency (HC) refiners used for thermomechanical pulp (TMP) and chemithermomecanical pulp (CTMP) production. This means that they are constructed to handle large flow and installed motor power is rather low. The normal gross specific refining energy for LC refining of mechanical pulp is around 50 to $150 \mathrm{kWh} / \mathrm{t}$ and the largest motor size is normally up to $2.5 \mathrm{MW}$.

Let's look on an example in the Holmen Paper mill Braviken, Norrköping, Sweden. The reject treatment in one of the TMP lines was rebuilt in 2003. The goal was to replace an old atmospheric RL58 HC refiner with a new pressurized HC refiner and second stage LC refining. The goal was to be able to apply high specific energy in the LC stage, up to $300 \mathrm{kWh} / \mathrm{adt}$. The production was around $7 \mathrm{adt} / \mathrm{h}$ which corresponds to a flow of $44 \mathrm{l} / \mathrm{s}$ at $4 \%$ consistency. At this production and specific energy the needed power is 2.1 MW, which made it necessary to install a TwinFlo 58 (or similar other refiner). The alternative would have been to install two smaller refiners in series. This is more costly though, and thus a TwinFlo 58 was installed. But, $44 \mathrm{l} / \mathrm{s}$ is a too low flow for a TF58 refiner, hence recirculation of refined pulp back to the feed pump was the solution to keep the flow through the refiner high enough, around $100 \mathrm{l} / \mathrm{s}$. Thus, recirculation can be used as a tool to be able to apply high specific energy in one LC refining stage, which also has been reported by Sandberg et al. (2009).

Lumiainen (2000) mentioned that recirculation is a way to "ensure sufficient fibre flow through the refiner in all conditions". So, recirculation has also been used as a tool to make sure that a refiner has stable and enough flow at varying production.

One of the first publications on the subject is the patent on flow recirculation by Jones (1964). He states that recirculation helps to keep the grooves (called "radial passageways" in the patent) flooded and the bars ("blades" in the patent) lubricated. This would reduce the wear of the "blades" and maintain the pulp quality at low production. Similar statements have also been presented later (Antku 1984, Rihs, Josephson 1997).

Different opinions have been presented on the effect of flow recirculation on LC refining efficiency and pulp properties development. In two papers no effect was found of recirculation on softwood kraft pulp properties (Kirby 1980, Rihs, Josephson 1997). In another study it was found that recirculation had a negative impact on kraft pulp strength development (Nuttall et al. 1999).

Kerekes (2014) made a thorough theoretical analysis of the effect of recirculation on refining conditions. He showed that, increased recirculation will not affect the total refining energy, but will have a large effect on the distribution of refining energy on the pulp due to that some fibres pass the refiner only one time and other fibres may pass several times. However no analysis of the impact on pulp properties was made.

The present work was made within the program "Energy Efficient Mechanical Pulping - Research Profile" at Mid Sweden University, Sweden. In that program one goal is to increase the specific energy in LC refining. As mentioned above, large recirculation can be one tool to increase the specific energy in one refiner. The question is whether recirculation is detrimental for pulp quality or energy efficiency, as could be indicated by the theoretical analysis of Kerekes (2014). In order to answer that question, two mill trials were performed.

\section{Materials and Methods}

Two TwinFlo EMA 52-58 (Andritz) were used for the trial. Both refiners were operating on Norway Spruce TMP, one in Holmen Paper Braviken and the other in Holmen Paper Hallstavik, Sweden. The two refiners have similar installations shown in Fig 1. 
TwinFlo refiners have a floating rotor and separate outlets from the two refining zones. The two outlet flows are mixed and in Hallstavik and Braviken an adjustable part of the mixed flow is fed back to the suction side of the feed pump. Both refiners studied in this work were equipped with LemaxX segments TC111/112. Rotational speed was $427 \mathrm{rpm}$. Definition of recirculation is: (flow through - flow forward)/flow through. Operation parameters for the two trials are shown in Table 1 and 2 .

Feed and outlet samples were taken as composite samples during $10 \mathrm{~min}$. Pulps from the Braviken trial were tested two times and pulps from the Hallstavik trial were tested three times and are presented as mean values. In the Braviken trial, handsheets were made with a RapidKöthen, ISO 5269-2, and in the Hallstavik trial according to a modified (handsheets were dried in a heated drum drier) SCAN-CM:26:99 method. Length weighted fibre length and shives content were analysed with a Eurocon PulpEye.

\section{Results and Discussion}

During the Braviken trial without recirculation, i.e. at low flow through the refiner, the outlet pressure was more unstable as can be seen in Fig 2. The gage pressure in one of the outlets (the drive-side) is shown for a period of two hours for both trials. The relative pressure variation was though similar for the two trials since the outlet pressure was on a higher level for the trial without recirculation. There was no significant difference in power variation for the two modes of operation. In order to achieve as stable refining process as possible, it is good to keep the flow through the refiner constant and on a high enough level. The optimal flow will of course depend on the size of the

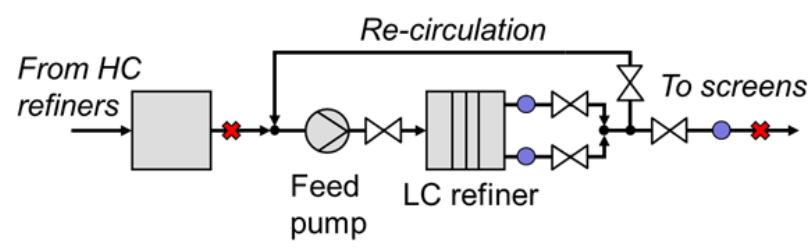

Fig 1 - Refiner system, where pulp sampling points (飞) and flow meters (O) are shown.

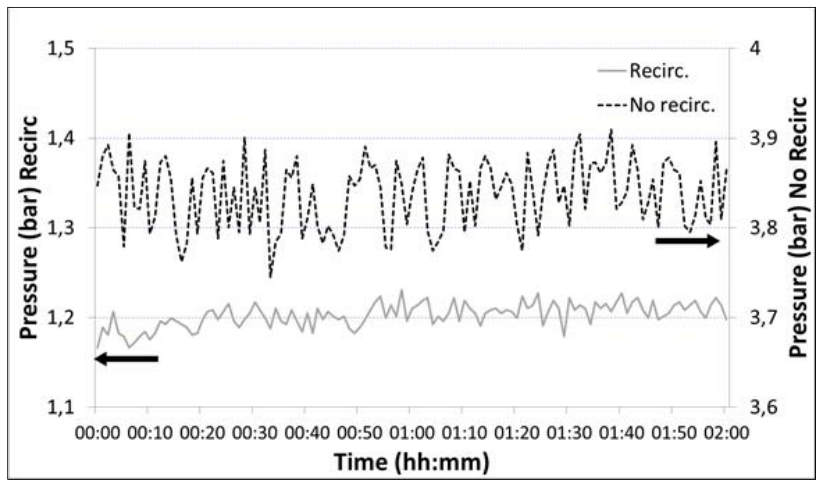

Fig 2 - Pressure (gage) at one of the outlets for operation with and without recirculation in the Braviken trial. refiner and this was not studied for the TF58 refiners in this work. It also has to be kept in mind that increased flow through a LC refiner need more pumping energy, which will reduce the overall energy efficiency. Also in the Hallstavik trial larger absolute pressure variations was seen at low flow $(4.0 \pm 0.09 \operatorname{bar}(\mathrm{g})$ compared to $2.5 \pm$ 0.05 bar(g)).

In Table 3 and 4 the pulp properties of feed and outlet samples from the two mill trials are shown for the different operating conditions. There are no large differences between the operation with recirculation and without recirculation.

In the Braviken trial the freeness drop and tensile index increase were somewhat larger for the trial with recirculation, but on the other hand fibre length and tear index reduction were also somewhat larger. In the Hallstavik trial recirculation was changed in two different ways - by increasing the flow through and by changing the flow forward. There was no difference in tensile index increase or freeness drop over the refiner for the two recirculation trials compared to the trial without recirculation. There was though a similar tendency as in Braviken with somewhat higher fibre length reduction at the high recirculation trial (Recirc.2) which can be seen in Fig 3.

One definition of refining energy efficiency is the increase in tensile index that is achieved with a certain specific energy i.e. Nm/g per MWh/adt. For the Braviken trial the recirculation trial had somewhat higher energy efficiency, 54 compared for 42 without recirculation. This was not confirmed in the Hallsta trial where the efficiency was around 45 for all configurations, Fig 4.

Table 1 - Process parameters and variables for Braviken trial

\begin{tabular}{lccc}
\hline & & Recirc. & No recirc. \\
\hline Power & $\mathrm{MW}$ & 1.61 & 1.63 \\
Consistency & $\mathrm{g} / \mathrm{l}$ & 41 & 41 \\
Flow through & $\mathrm{l} / \mathrm{s}$ & 134 & 72 \\
Flow forward & $\mathrm{l} / \mathrm{s}$ & 75 & 75 \\
Recirculation & $\%$ & 43 & 0 \\
Feed pressure & $\mathrm{bar}(\mathrm{g})$ & 1.9 & 1.9 \\
Outlet pressure & $\mathrm{bar}(\mathrm{g})$ & 1.2 & 3.8 \\
Production forward & $\mathrm{adt} / \mathrm{h}$ & 12.5 & 12.3 \\
Specific energy & $\mathrm{kWh} / \mathrm{adt}$ & 129 & 133 \\
Specific edge load & $\mathrm{J} / \mathrm{m}$ & 0.56 & 0.56 \\
\hline
\end{tabular}

Table 2 - Process parameters and variables for Hallstavik tria

\begin{tabular}{lcccc}
\hline & & Rec. 1 & Rec.2 & No rec. \\
\hline Power & MW & 1.06 & 1.47 & 1.45 \\
Consistency & $\mathrm{g} / \mathrm{l}$ & 45 & 45 & 45 \\
Flow through & $\mathrm{l} / \mathrm{s}$ & 110 & 170 & 110 \\
Flow forward & $\mathrm{l} / \mathrm{s}$ & 80 & 110 & 110 \\
Recirculation & $\%$ & 27 & 35 & 0 \\
Feed pressure & $\mathrm{bar}(\mathrm{g})$ & 2.0 & 1.6 & 2.0 \\
Outlet pressure & $\mathrm{bar}(\mathrm{g})$ & 4.4 & 2.5 & 4.0 \\
Production forward & $\mathrm{adt} / \mathrm{h}$ & 14.4 & 19.8 & 20.0 \\
Specific energy & $\mathrm{kWh} / \mathrm{adt}$ & 74 & 74 & 73 \\
Specific edge load & $\mathrm{J} / \mathrm{m}$ & 0.29 & 0.46 & 0.45 \\
\hline
\end{tabular}




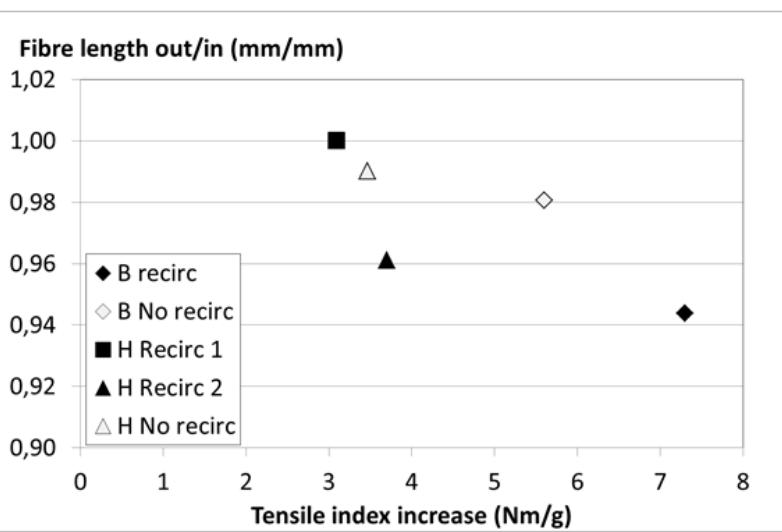

Fig 3 - Fibre length outlet / Fibre length inlet versus tensile index increase over refiners in Braviken (B) and Hallstavik (H).

Table 3 - Pulp properties Braviken trial

\begin{tabular}{llcccc}
\hline & & \multicolumn{2}{c}{ Recirc. } & \multicolumn{2}{c}{ No recirc. } \\
& & Feed & Outlet & Feed & Outlet \\
\hline CSF & $\mathrm{ml}$ & 180 & 139 & 170 & 141 \\
Fibre length & $\mathrm{mm}$ & 1.34 & 1.26 & 1.29 & 1.27 \\
Shives sum & $\# / \mathrm{g}$ & 1066 & 823 & 971 & 763 \\
Tensile index & $\mathrm{Nm} / \mathrm{g}$ & 44.0 & 51.3 & 46.0 & 50.6 \\
Tear index & $\mathrm{Nm} 2 / \mathrm{kg}$ & 8.8 & 7.8 & 8.3 & 7.9 \\
Density & $\mathrm{kg} / \mathrm{m}^{3}$ & 474 & 495 & 478 & 495 \\
\hline
\end{tabular}

Table 4 - Pulp properties Hallstavik trial

\begin{tabular}{llcccccc}
\hline & & \multicolumn{2}{c}{ Recirc. 1 } & \multicolumn{2}{c}{ Recirc. 2 } & \multicolumn{2}{c}{ No recirc. } \\
& & Feed & Outlet & Feed & Outlet & Feed & Outlet \\
\hline CSF & $\mathrm{ml}$ & 120 & 99 & 122 & 99 & 117 & 96 \\
$\begin{array}{l}\text { Fibre } \\
\text { length }\end{array}$ & $\mathrm{mm}$ & 1.02 & 1.02 & 1.03 & 0.99 & 1.03 & 1.02 \\
$\begin{array}{l}\text { Shives } \\
\text { sum }\end{array}$ & $\# / \mathrm{g}$ & 381 & 286 & 397 & 319 & 467 & 341 \\
$\begin{array}{l}\text { Tensile } \\
\text { index }\end{array}$ & $\mathrm{Nm} / \mathrm{g}$ & 41.0 & 44.1 & 40.9 & 44.6 & 40.8 & 44.3 \\
$\begin{array}{l}\text { Tear } \\
\text { index }\end{array}$ & $\mathrm{Nm} 2 / \mathrm{kg}$ & 7.9 & 7.3 & 7.5 & 7.2 & 7.5 & 7.2 \\
Density & $\mathrm{kg} / \mathrm{m}^{3}$ & 308 & 334 & 314 & 317 & 315 & 353 \\
\hline
\end{tabular}

The difference in Braviken can be caused by scatter in the tensile index measurement. The efficiency for LC refining is normally around 45 (Sandberg et al. 2009). The results indicate that recirculation does not have a negative effect on energy efficiency (as defined here).

One concern before the trials was that recirculation might result in a more inhomogeneous fibre treatment i.e. a wider distribution in fibre properties, as indicated by Kerekes (2014). The pulps from the Braviken trial were therefore analysed with a modified Simon's Stain method in order to detect any differences in fibre wall treatment (Fernando, Daniel 2010). The analyses were made by the Swedish University of Agricultural Sciences (SLU). By Simon's Stain the fibres are classified according to different degree of fibre wall treatment (delamination (D), internal fibrillation (IF)). In Fig 5 the black bars are the least treated and the light grey bars the most treated fibres.

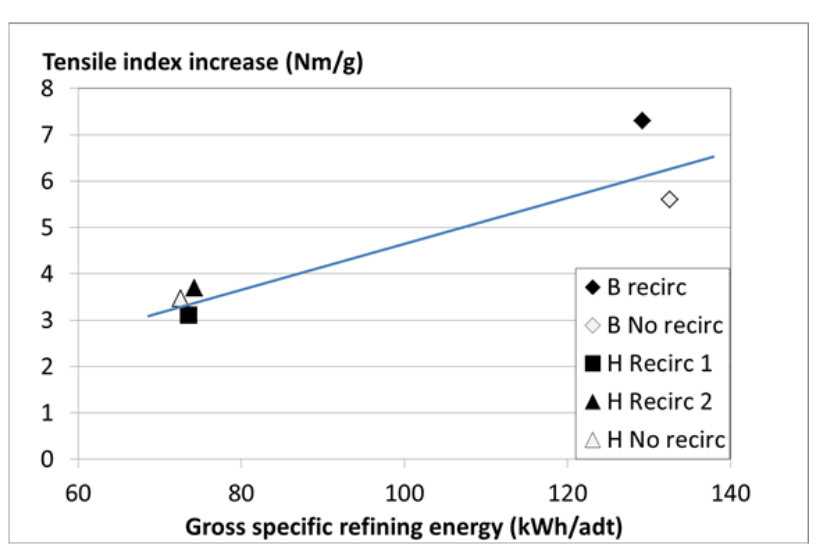

Fig 4 - Tensile index increase over refiners in Braviken (B) and Hallstavik $(H)$ versus specific refining energy. The line represent efficiency 45 (Nm/g)/(MWh/adt).

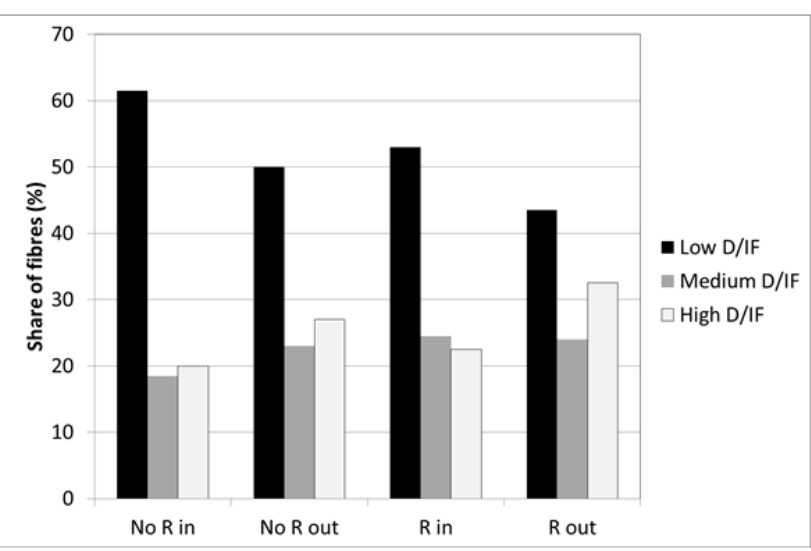

Fig 5 - Fibre wall treatment measured with the modified Simons' Stain method for $L C$ refining with recirculation $(R)$ and without recirculation (No R). Black represents fibres with low treatment and light grey high treatment.

No significant difference in the fibre development between recirculation and no recirculation could be detected on the fibre wall level by this method. Both modes of operation resulted in a reduction of poorly treated fibres and increased amount of highly refined fibres.

Based on these conditions and measurements, no effect of recirculation on refining efficiency (defined as increase of tensile index per applied specific energy) and fibre treatment distribution could be seen. This means that a large degree of recirculation can be used to attain high specific energy in one stage low consistency refining, without significant negative effects on fibre properties.

One explanation to the observation that there is little effect on fibre development by recirculation when recirculation is increased by means of increased flow through the refiner could be decreased internal recirculation. Earlier work has shown that there is internal recirculation in LC refiners that depend on the differential pressure over the refiner (Wittberg et al. 2012). At high flow through the refiner, the outlet pressure was much lower, in the Braviken trial even lower than the feed pressure. Hence the internal recirculation probably decreased when the external recirculation increased. This means that the distribution in fibre treatment might not increase so much when the 
outer recirculation is increased, since the internal recirculation might be reduced simultaneously. This change in the internal recirculation at changed flow was not discussed by Kerekes (2014) in his theoretical analysis.

Although no large differences in pulp quality could be seen upon changes in degree of flow recirculation in this investigation, there might still be an effect of large degree of recirculation on i.e. printing properties. It is easy to imagine that the share of coarse fibres that will slip through the refiner at high flow might increase and such fibres are negative for the print quality (Høydahl, Dahlqvist 1997). That effect was not investigated in this work, but will be looked upon in further work.

\section{Conclusions}

In this study, the effect of flow recirculation on pulp properties development and energy efficiency in low consistency refining has been investigated. Trials with two TwinFlo 58 refiners in Braviken and Hallstavik paper mills showed that recirculation:

- Does not have a large effect on the pulp property development. There was though a somewhat larger fibre length reduction at high recirculation

- Does not affect energy efficiency

- Does not notably change the distribution in fibre wall delamination/internal fibrillation

- Helps to keep the refiner in more stable operation.

- Can be used to attain a high specific energy in one stage low consistency refining.

\section{Acknowledgements}

The authors are most grateful to the Knowledge Foundation and Holmen Paper $A B$ for financial support and to Per Engstrand for valuable comments on the manuscript.

\section{Literature}

Antku, J. (1984): Maintaining minimum flow requirements of the twin-disc refiner, Tappi J. 67(10): 112.

Fernando, D. and Daniel, G. (2010): Characterisation of spruce thermochemical pulps at the fibre cell wall level: a method for quantitatively assessing pulp fibre development using Simons' stain. Tappi J., 9(10), 47-55.

Høydahl, H.-E. and Dahlqvist, G. (1997) The dual demand on fibres in SC papers, Int. Mech. Pulping Conf., Stockholm, 337344.

Jones, D. E. (1964): Recirculating disk refiner, Patent US 3,118,622.

Kerekes, R. J. (2014): A theoretical analysis of recirculation in pulp refiners, Tappi J., 13 (4), 29-32

Kirby, P.L., (1980): Analysis of a mill refiner system using specific edge load theory, Appita J. 34(1): 25.

Lumiainen, J. (2000): Refining of chemical pulp, In: Paulapuro, H. (ed.), Papermaking Science and Technology, Book 8, Papermaking Part 1, Stock preparation and wet end, Fapet Oy, Helsinki, Finland, pp. 86-122.

Nuttall, G. H., Mott, L. and Mayhead, G. (1999): The influence of key refining variables on energy use, Paper Technol. 4(7): 75

Rihs, J. and Josephson, W. E. (1997): Refining systems with flow recirculation, PIRA Int. Refin. Conf., 4th, Smithers Pira, Leatherhead, UK, p. 1.

Sandberg, C. Sundström, L. and Nilsson, L. (2009): Potential of low consistency refining of TMP - mill evaluation, Int. Mech. Pulping Conf., Sundsvall, Sweden, pp. 186-189.

Wittberg, L., Björkman, M., Khokhar, G., Mohlin, U-B and Dahlkild, A. (2012): Flow conditions in the grooves of a LowConsistency refiner, Nordic Pulp Paper Res. J. 27(2), 173-183.

Manuscript received November 5, 2014 Accepted November 25, 2014 